\title{
Testing For The Purchasing Power Parity Hypothesis In A Small Open Economy: A VAR-X Approach
}

Lumengo Bonga-Bonga, University of Johannesburg, South Africa

\begin{abstract}
This paper tests the purchasing power parity (PPP) hypothesis for the rand-US dollar exchange rate by making use of the cointegrating VAR-X approach. Given that the test of PPP hypothesis conducted in this paper involves variables of a small economy, South Africa, compared to a big economy, the US, the paper contends that traditional cointegrating VAR approach that considers all variables in a given vector as endogenous is not suitable. The results of the paper show that the restriction applied in the cointegrating vector for the VAR-X model supports the weak-form PPP hypothesis. The same restrictions are rejected in the case of traditional cointegrating VAR model. The paper concludes that it is essential to distinguish between weakly exogenous and endogenous variables in tests of the PPP hypothesis that involve small and big economies.
\end{abstract}

Keywords: Purchasing Power Parity; Cointegrating VAR-X; Exchange Rates

\section{INTRODUCTION}

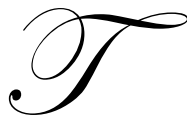

he purchasing power parity (PPP) is probably the most debated theory of exchange rate determination. The theory holds that the nominal exchange rate between two currencies should be equal to the ratio of aggregate price levels between the two countries. Moreover, the PPP expression is used to derive the real exchange rate - that is, the nominal exchange rate multiplied by the ratio of foreign and domestic price levels. The link between the PPP expression and the real exchange rate is instrumental for testing the PPP hypothesis. Thus, if PPP holds, the real exchange rate should be equal to unity or stationary. The stationarity of the real exchange rate, which implies support for the PPP hypothesis, also entails that the nominal exchange rate and relative prices are cointegrated, or, equivalently, have a common stochastic trend. This reality implies that testing the PPP hypothesis can be carried out by testing the stationarity of the real exchange rate or by assessing the possibility of a common stochastic trend between the nominal exchange rate and the relative prices between two countries.

The rationale behind the PPP is related to the principle of arbitrage opportunity or riskless profit. That is, if two identical products are traded at different prices in different countries, a profitable arbitrage opportunity arises if the arbitrageurs can buy the good cheaply in one location and sell it at a higher price in the other given the nominal bilateral exchange rate. If arbitrage opportunity is then precluded, this process leads to the convergence of the deviations from PPP towards zero, or the long-term equilibrium is established between bilateral nominal exchange rate and relative prices in the two locations.

Studies that have used cointegration techniques to test the PPP hypothesis make a distinction between the weak and strict form. The weak form of PPP assumes that exchange rates are in equilibrium and that there is a longterm relationship between exchange rates and relative prices. However, in its strict form, the PPP holds that there is a one-on-one equilibrium relationship between nominal exchange rates and relative prices.

Moreover, a number of studies in developed and developing economies alike recommend the use of a nonlinear model rather than a linear model when testing for the PPP. For example, Taylor and Taylor (2004) suggest 
that allowing for non-linear dynamics in real exchange rate adjustment may solve the PPP puzzle phenomenon discussed in many studies on exchange rate determination. Also, Hang and Basher (2011) argue that a non-linear relationship is a plausible model for PPP, and that it is essential to explore whether it is consistent with the data.

As regards studies on the testing of PPP in South Africa, Mokoena et al.(2009) test the mean reversion characteristic of the different real exchange rate by comparing non-linear and linear tests of non-stationarity. The authors find that, in comparison with linear tests, non-linear approaches to exchange rate adjustment provide firm support for the PPP in the long term. Lacerda et al. (2010) test the PPP and uncovered interest parity (UIP) in the presence of monetary and exchange rate regime shifts in South Africa. The authors find that the Markov-switching vector error correction model (VECM), rather than the standard linear VECM, provides strong evidence in favour of both the PPP and UIP relationship.

The proponents of non-linear adjustment approaches to testing PPP contend that the mean reverting process in the PPP relation is asymmetric due to the presence of transaction cost (Michael et al., 1997; Villavicencio, 2008). Transaction cost creates a band of inaction whereby arbitrageurs refrain from participating in the foreign exchange market even though there is a disequilibrium in the PPP relation. The mean-reverting processing of the PPP relationship occurs only if the profit expected by arbitrageurs outweighs the transaction cost. Thus, econometric methods related to non-linear approaches such as the smooth transaction process, the class of Markov-switching methods and other non-linear methods have become prominent in testing for the PPP hypothesis given their capacity to explain asymmetric adjustment process (Taylor, 2009). Nonetheless, a number of studies that claimed to have resolved the PPP puzzle by applying non-linear methodologies, to the detriment of linear methodologies, have failed to provide a proper specification of the linear model that they reject. Ultimately, those studies have made use of inappropriate specifications of linear models. One of the common misspecifications in the use of linear models for testing the PPP hypothesis occurs in the context of cointegrating VAR methodology.

In fact, in the context of cointegrating VAR methodology the testing of the PPP hypothesis implies a linear restriction in the cointegrating vector constituted by strictly endogenous variables, namely the nominal exchange rate, and the domestic and foreign price levels variables (see for example, Johansen and Juselius (1992) and Pesaran and Shin (1996)). This assumption may not hold when the testing of the PPP hypothesis involves a small open economy and a relatively big economy. For example, Pesaran et al. (2000) show that it is unlikely that changes in domestic variables have significant effects on the long-run evolution of foreign variables, especially in the case of small open economies.

Although a number of studies have taken cognisance of the reality that some of the variables should be treated as weakly exogenous when testing the PPP hypothesis in the context of cointegrating VAR, these studies did not specify a sub-system within which these exogenous variables should be determined (see Lacerda et al., 2010; Sideris, 2006; Cushman, 2008). In fact, without a sub-system within which exogenous variables are determined, these variables are treated as strongly rather than weakly exogenous. Given this shortcoming, the contribution of this paper will consist in applying the cointegrating VAR-X approach, as pioneered by Pesaran et al. (2000), in testing the PPP hypothesis between South Africa and the US. The cointegrating VAR-X approach is a generalisation of the Johansen $(1991,1995)$ approach to cointegration in that it introduces a sub-system representation for exogenous variables in the VAR system and any cointegrating relation present in the system does not appear in the sub-system of these exogenous variables. This approach is relevant to the present case where the testing of the PPP hypothesis involves South Africa, a small open economy compared to the US. It is rational to assume a priori that among the variables included in the cointegrating vector in the present case of the testing of the PPP hypothesis, the price level in the US is considered weakly exogenous and thus included in the sub-system model and the main cointegrating vector.

The remainder of the paper is arranged as follows: Section 2 presents the VAR-X approach to the cointegration method, sector 3 discusses the data and the results of the testing of PPP, and Section 4 concludes the paper. 


\section{THE VAR-X APPROACH TO COINTEGRATION}

The cointegrating VAR-X model, also known as the Gaussian cointegrating VAR with exogenous variables, is applied in the case when the VAR system contains exogenous variables that are generally integrated at order one, I(1), or are non-stationary. The cointegrating VAR-X approach necessitates that the cointegrating vector among those exogenous variables be estimated in the marginal sub-system.

Consider a VAR model with I(1) exogenous variables:

$Y_{t}=\sum_{i=1}^{p} \Pi_{Y i} Y t-1+\sum_{i=1}^{p} \Pi_{Y X i} X_{t-1}+\varepsilon_{Y t}$

where the I(1) exogenous variable $X_{t}$ is assumed to be generated independently by the following sub-system:

$$
X_{t}=\sum_{i=1}^{p} \Pi_{X i} X_{t-i}+\varepsilon_{X t}
$$

where $\Pi_{Y}, \Pi_{X Y}$ and $\Pi_{X}$ are coefficient matrices. The error vectors $\varepsilon_{X}$ and $\varepsilon_{Y}$ are uncorrelated and assumed to be independently and identically normal.

Equations 1 and 2 can be reparameterised to yield:

$$
\begin{aligned}
& \Delta Y_{t}=\sum_{i=1}^{p-1} \Gamma_{Y i} \Delta Y_{t-i}+\sum_{i=0}^{p-1} \Gamma_{Y X i} \Delta X_{t-i}+\Pi_{Y} Y_{t-1}+\Pi_{Y X} X_{t-1}+\varepsilon_{Y t} \\
& \Delta X_{t}=\sum_{i=1}^{p-1} \Gamma_{X i} \Delta X_{t-i}+\Pi_{X} X_{t-1}+\varepsilon_{X t}
\end{aligned}
$$

where $\Pi_{Y}=\alpha_{Y} \beta_{Y}^{\prime}$ and $\Pi_{X}=\alpha_{X} \beta_{X}^{\prime}$. The matrices $\alpha$ and $\beta$ contain the loading coefficients and the coefficient of the cointegration relations, respectively. The coefficients $\Gamma$ are the short-run parameters. Contrary to the Johansen method of cointegration, Equations 3 and 4 indicate that some of the cointegration vectors in the full system involve the I(1) exogenous variables. It is important to note that in this full system $\beta_{X}^{\prime} X_{t-1}$ represents the equilibrium condition in the exogenous variables, which are stationary and affect the dynamic of $Y_{t}$ through $\Pi_{Y X}$. It is for this reason that Mosconi and Giannini (1992) suggest that an assumption should be made on $\Pi_{Y X}$ in order to avoid the $\mathrm{I}(1)$ process $X_{t}$ generating a higher-order integration in $Y_{t}$. The authors recommend the following assumption:

$$
\Pi_{Y X}=\alpha_{Y} \varphi^{\prime} \gamma_{X}^{\prime}+\alpha_{Y X} \beta_{X}^{\prime}
$$

Thus, if the assumption made in Equation 5 is considered, Equation 3 is reparameterised to yield:

$$
\Delta Y_{t}=\sum_{i=1}^{p-1} \Gamma_{Y i} \Delta Y_{t-i}+\sum_{i=0}^{p-1} \Gamma_{Y X i} \Delta X_{t-i}+\alpha_{Y} \beta_{Y}^{* \prime}\left[\begin{array}{l}
Y_{t-1} \\
\gamma_{X}^{\prime} X_{t-1}
\end{array}\right]+\alpha_{Y X}\left(\beta_{X}^{\prime} X_{t-1}\right)+\varepsilon_{Y t}
$$


Equations 4 and 6, taken together, may be written as

$$
\Delta Z_{t}=\sum_{i=1}^{p-1} \Gamma_{Z_{i}} \Delta Z_{t-1}+\alpha_{Z} \beta_{Z}^{\prime} Z_{t-1}+\varepsilon_{Z t}
$$

where

$$
Z_{t}=\left[\begin{array}{l}
Y_{t} \\
X_{t}
\end{array}\right], \Gamma Z i=\left[\begin{array}{cc}
\Gamma_{Y i} & \Gamma_{Y X i} \\
0 & \Gamma_{X i}
\end{array}\right], \alpha_{Z}=\left[\begin{array}{ll}
\alpha_{Y} & \alpha_{Y X} \\
0 & \alpha_{X}
\end{array}\right], \beta_{Z}^{\prime}=\left[\begin{array}{ll}
\beta_{Y} & \gamma_{X} \varphi \\
0 & \beta_{X}
\end{array}\right]
$$

The decomposition of Equation 7, denoted in Equation 8, indicates that some of the cointegration vectors involve the exogenous variables only and these vectors are represented in the sub-system with non-zero loading variables. Moreover, the stationarity of the exogenous variable $\beta_{Z}^{\prime} X_{t-1}$ affects the dynamics of $Y_{t}$, while no feedback effect is allowed in the full system. Thus, the cointegration relationship exists between $Y_{t}$ and $X_{t}$ under the condition that $Y_{t}$ does not Granger-cause $X_{t}$.

\section{DATA AND EMPIRICAL ANALYSIS}

A number of studies have shown that linear models, especially linear cointegrating models, have a tendency to reject the PPP hypothesis. Nonetheless, this paper shows that this occurrence is due to the misspecification of linear cointegrating models. The hypothesis supported by this paper is that a testing of the PPP hypothesis that involves a small open economy and a relatively big economy should be able to distinguish between endogenous and weakly exogenous variables. Thus, this paper will compare the results of the PPP hypothesis using the case of 'traditional' cointegrating VAR, whereby all the variables necessary to test the PPP hypothesis are treated as endogenous, and the case where some of the variables are treated as weakly exogenous.

The PPP hypothesis this paper intends to test is expressed as:

$e_{t}+\beta_{1} P_{t}-\beta_{2} P_{t}^{*} \approx \mu_{t}$

The weak form of PPP hypothesis holds if the three variables, namely $e_{t}, P_{t}$ and $P_{t}^{*}$, are each I(1) and that their linear combination, $\mu_{t}$, is covariance stationary or $\mathrm{I}(0)$. Thus, for the weak-form PPP hypothesis to hold, the linear combination or the cointegrating vector $\left(1, \beta_{1},-\beta_{2}\right)$ is stationary. Nonetheless, in the case of strict PPP the linear combination $(1,1,-1)$ between the three variables should be stationary.

In this paper, $e_{t}$ represents the natural logarithm of the nominal rand/dollar exchange rate. $P_{t}$ and $P_{t}^{*}$ are the natural logarithm of the Producer Price Index (PPI), with base year 2000 for South Africa and the United States respectively. The empirical analysis makes use of quarterly data from 1972Q2 to 2007Q1. The end sample period corresponds to the period before the global financial crisis. Thus, this paper tests the PPP hypothesis that involves South Africa and the US before the global financial crisis. It is worth noting that Lacerda et al. (2010) indicate that PPI is preferred to the Consumer Price Index (CPI) when testing the PPP hypothesis. This is because the latter is likely to bias the results in favour of the PPP hypothesis, since the basket of goods that constitutes the CPI in South Africa includes goods imported from the US, which are also included in the CPI of the US. 
The assumption of this paper is that because the proposed testing of the PPP hypothesis involves a small open economy, South Africa, and a relatively bigger economy, the US, it is evident that $P_{t}^{*}$, a I(1) variable, is presumed to be weakly exogenous in the cointegrating equation(s) constituted by $e_{t}, P_{t}$ and $P_{t}^{*}$ - hence the importance of the use of cointegrating VAR-X rather than the traditional cointegrating VAR model.

The paper will compare the estimation of the restricted cointegration relations relative to the PPP hypothesis for both VAR and VAR-X models. The starting point of the analysis is the unit root test applied to the three variables. Table 1 reports the results of the Dickey-Fuller generalised least squares (DF-GLS) test of the null hypothesis of unit root. This test is chosen because of its improved power over the traditional augmented DickeyFuller (ADF) test (Lai, 2008). The results reported in Table 1 show that all the variables are integrated at order one (I(1)). Thus, it is important to conduct the test of cointegration to determine the cointegration rank of the PPP model as in Equation 9.

Table 1: Unit Root test of different series: DF-GLS test statistics

\begin{tabular}{lccc}
\hline Variables & Level & First Difference & Order of Integration \\
$e_{t}$ & 1.4854 & $-10.7367 *$ & $\mathrm{I}(1)$ \\
$P_{t}$ & 0.3493 & $-4.5109 *$ & $\mathrm{I}(1)$ \\
$P_{t}^{*}$ & 0.6976 & $-3.4303 *$ & $\mathrm{I}(1)$ \\
\hline$*$ and $* *$ indicate rejection of the null hypothesis of unit root at the 1\% and 5\% levels, respectively.
\end{tabular}

We carry out a test of cointegration treating $P_{t}^{*}$ as I(1) and weakly exogenous, and thus long-run forcing for $e_{t}$ and $P_{t}$. The order of the VAR-X selected on the basis of Akaike Information Criteria is 2.

The results of the maximum eigenvalue cointegration rank statistics on VAR-X(2,2), reported in Table 2, reject the null hypothesis of no cointegration at the 5\% significance level, and indicate the existence of one cointegrating relationship.

Table 2: Test of Cointegration: Maximum eigenvalue cointegration rank statistics

\begin{tabular}{ccccc}
\hline Null & Alternative & Statistics & \multicolumn{2}{c}{ Critical values } \\
& & & $95 \%$ & $90 \%$ \\
$\mathrm{r}=0$ & $\mathrm{r}=1$ & 72.5167 & 18.88 & 16.74 \\
$\mathrm{r}<=1$ & $\mathrm{r}=2$ & 6.194 & 12.45 & 10.5 \\
\hline
\end{tabular}

With the knowledge that there is one cointegrating relationship among the three variables, Table 3 presents the results of the maximum likelihood of the estimates of the restricted cointegrating relations among the three variables in a traditional cointegrating VAR model. This model assumes that all the variables in the system are endogenous. It is important to note that the over-identifying restriction on the unique cointegrating vector reported in Table 3 implies the normalisation of the coefficient of $e_{t}$ as well as the co-trending hypothesis $(T=0)$ between $e_{t}, P_{t}$ and $P_{t}^{*}$. These restrictions are applied in order to test the weak-form PPP hypothesis under the assumption that the three series co-trend.

The likelihood ratio (LR) test of the imposed restriction has a Chi-square $\left(\chi^{2}(1)\right)$ statistic of 12.9035 . Given the estimated $95 \%$ and $90 \%$ bootstrapped critical values of 6.8317 and 4.6140 , the null hypothesis of a weakform PPP under the co-trending assumption is rejected. This finding indicates that the weak-form PPP hypothesis does not hold if all variables are considered as endogenous in the VAR system. 
Table 3: Imposed restrictions on the cointegrating vector of the VAR model

\begin{tabular}{cc}
\hline Variables & Vector \\
\hline$e_{t}$ & 1.00 \\
$P_{t}$ & -1.5757 \\
$P_{t}^{*}$ & 2.3005 \\
$T$ & 0.00 \\
\hline
\end{tabular}

Note: $T$ represents the trend in the cointegrating relation between the three variables

LR Test of Restrictions $\quad \chi^{2}(1)=12.9035$

95\% Bootstrapped Critical Value $=6.8317$

90\% Bootstrapped Critical Value $=4.6140$

In the next step, the same restriction as in the above cointegrating VAR model is carried out in the context of the VAR-X model. The VAR-X model assumes that $P_{t}^{*}$ enters the cointegrating relationship as a weakly exogenous variable. Table 4 provides the estimation of the VAR-X model under the imposed restrictions of weakform PPP and the co-trending assumption.

Table 4: Imposed restrictions on the cointegrating vector of the VAR-X model

\begin{tabular}{cc}
\hline Variables & Vector \\
\hline$e_{t}$ & 1.0000 \\
$P_{t}$ & -1.7213 \\
$P_{t}^{*}$ & 2.5253 \\
$T$ & 0.0000 \\
\hline
\end{tabular}

LR Test of Restrictions $\quad \chi^{2}(1)=5.4068$

95\% Bootstrapped Critical Value $=6.9019$

Bootstrapped simulations based on 1000 simulations.

The results reported in Table 4 show that the null hypothesis of the weak-form PPP hypothesis is not rejected given the $95 \%$ bootstrapped critical value. This confirms that the weak-form PPP hypothesis holds if the imposed restriction relative to this hypothesis PPP test is carried out in a cointegrating VAR that assumes the coexistence of endogenous and weakly exogenous variables. In the present case, where the weak-form PPP hypothesis is tested in a vector constituted by $e_{t}, P_{t}$ and $P_{t}^{*}$, variable $P_{t}^{*}$ is assumed to be weakly exogenous, as it is not expected that domestic variables such as the rand-dollar exchange rate and Producer Price Index in South Africa will influence domestic prices in the US. Moreover, the results presented in Table 4 show that the co-trending assumption is important in testing the PPP hypothesis in the case of South Africa and the US. In fact, Figure 1 confirms that the three variables are trending.

A further analysis to test whether strict PPP hypothesis holds in South Africa is carried out by using the cointegrating VAR-X approach. It is important to note that the strict PPP hypothesis holds if the null hypothesis of the imposed restriction $(1,1,-1)$ on the vector $Z_{t}=\left(e_{t}, P_{t}, P_{t}^{*}\right)$ is not rejected. Table 5 provides the results of the maximum likelihood estimation of the VAR-X model with the imposed restrictions relative to the strict PPP hypothesis. The results reported in Table 5 indicate that restrictions related to the null hypothesis of strict PPP are rejected. Thus, the strict PPP hypothesis does not hold in the case of South African and US variables. 
Table 5: Imposed restrictions on the cointegrating vector of the VAR-X model

\begin{tabular}{cc}
\hline Variables & Vector \\
\hline$e_{t}$ & 1.0000 \\
$P_{t}$ & 1.0000 \\
$P_{t}^{*}$ & -1.0000 \\
$T$ & 0.0000 \\
\hline
\end{tabular}

LR Test of Restrictions $\quad \chi^{2}(3)=20.5856$

95\% Bootstrapped Critical Value $=17.0917$

$90 \%$ bootstrapped critical Value $=14.3088$

Bootstrapped simulations based on 1000 simulations.

The support of the weak-form PPP hypothesis in the context of this paper is an indication that there is a long-term relationship or a common stochastic trend between the rand-dollar exchange rate and the relative price level in South Africa and the US. This implies that the rand-dollar exchange rate is affected by domestic variables in South Africa as well as external variables such as the Producer Price Index in the US. While the hypothesis of a common stochastic trend between $e_{t}, P_{t}$ and $P_{t}^{*}$ is proven under the weak-form hypothesis, this paper shows that the strict PPP, i.e. a one-on-one relationship among the three variables, does not hold for South African and US variables. A number of authors attribute the failure of the strict PPP hypothesis to differences of aggregate prices in different locations. For example, Froot and Rogoff (1995) attribute the difference in aggregate prices between different countries to the trading friction across a broad range of commodities due to tariff barriers, transportation costs and information costs. Moreover, another reason for the failure of the strict PPP hypothesis is statistical and may be due to the fact that aggregate domestic price, $P_{t}$, is error-correcting in the vector $Z_{t}=\left(e_{t}, P_{t}, P_{t}^{*}\right)$. In fact, the results of the weak exogeneity test of the variables in $Z_{t}$ in Table 6 show that the null hypothesis of the weak exogeneity of $P_{t}$ is rejected. Thus, $P_{t}$ is endogenous and error-correcting among the three variables, and consequently varies to re-establish the equilibrium of the system following shocks to $e_{t}$, even though $P_{t}^{*}$ remains constant. This reality indicates that in such situations it is impossible to maintain a one-on-one relationship between $P_{t}$ and $P_{t}^{*}$.

Table 6: Weak exogeneity test in the vector $Z_{t}=\left(e_{t}, P_{t}, P_{t}^{*}\right)$

\begin{tabular}{lcc}
\hline Restriction & $\chi^{2}(1)$ & Probability \\
\hline$\alpha\left(P_{t}\right)=0$ & 8.9157 & 0.002827 \\
$\alpha\left(P_{t}^{*}\right)=0$ & 0.2377 & 0.6259 \\
$\alpha\left(e_{t}\right)=0$ & 2.2212 & 0.136125 \\
\hline
\end{tabular}

Note: $\alpha\left(\right.$ ) is the loading factor. The null hypothesis of weakly exogenous variable is rejected for $P_{t}$.

\section{CONCLUSION}

This paper attempted to test whether the PPP hypothesis holds between South Africa and the US by making use of the cointegration approach. The paper argues that any cointegrating VAR approach to the testing of PPP should distinguish between endogenous and weakly exogenous variables within a specific vector. Thus, the paper supports the use of the cointegrating VAR-X approach to testing the PPP hypothesis between South Africa and the US. The results of the paper show that the weak-form PPP hypothesis holds between the two countries when PPP 
restrictions are applied to the cointegrating vector of the VAR-X model. Equivalent restrictions applied in a cointegrating VAR, i.e. a VAR model without weakly I(1) exogenous variables, have resulted in the rejection of the weak form of the PPP hypothesis. Moreover, the paper shows that the strict PPP hypothesis does not hold between South Africa and the US whatever cointegrating VAR model is used. This is attributed to the fact that aggregate prices are not assumed always to be equal between the two countries due to factors such as tariff barriers, transportation costs and information costs. In addition, the paper shows that strict PPP does not need to hold if domestic aggregate price level is a correcting variable in the common stochastic trend between the exchange rate, domestic and foreign aggregate price levels.

\section{AUTHOR INFORMATION}

Professor Bonga-Bonga is the current head of the Department of Economics and Econometrics at the University of Johannesburg, South Africa. He specializes in the fields of financial economics and Public finance. E-mail: lbonga@uj.ac.za

\section{REFERENCES}

1. Cushman, D.O., Long-run PPP in a system context: No favourable evidence after all for the US, Germany and Japan, Journal of International Financial Markets, institutions and Money, Vol. 18, No.5, pp. 413-424, 2008.

2. Froot, K.A., Rogoff, K., Perspectives on PPP and long-run real exchange rates. In: Grossman, G.,Rogoff, K. (Eds.), Handbook of International Economics, vol. III. North-Holland, Amsterdam, pp. 1647-1688. 1995.

3. Haug, A.A. and Basher, S., Linear or Nonlinear Cointegration in the Purchasing Power Parity Relationship?, Applied Economics Vol.43, No. 2, pp.185-196, 2011.

4. Johansen, S. and Juselius, K., Testing Structural Hypothesis in a Multivariate Cointegration Analysis of the PPP and the UIP for UK, Journal of Econometrics, Vol. 53, pp.211-244, 1992.

5. Johanssen, S Likelihood based inference on cointegration in the vector autoregressive model. Oxford: Oxford University, 1995.

6. Johanssen, S., Estimation and hypothesisitesting of cointegration vectors in Gaussian vector autoregressive models. Econometrica, Vol. 59, pp.1551-1580, 1995.

7. Lacerda, M., Fedderke, J.W. and Haines, L.M., Testing for Purchasing power parity and uncovered interest rate parity in the presence of monetary and exchange rate regime, South African Journal of Economics, Vol. 78, No. 4, pp. 344-362, 2010.

8. LAI, K.S., The Puzzling unit Root in the Real Interest Rate and its Inconsistency with Intertemporal Consumption Behavior. Journal of International Money and Finance, Vol. 27, No.1, pp. 140-155, 2008.

9. Michael, P., Nobay, A. R. and Peel, D. A., Transactions costs and nonlinear adjustment in real exchange rates: an empirical investigation, Journal of Political Economy, Vol. 105, No. 4, 862-79, 1997.

10. Mokoena, T.M., Gupta, R. and Van Eyden, R., Testing for PPP using SADC real exchange rates, South African Journal of Economics, Vol. 77, No. 3, pp.351-362, 2009.

11. Mosconi, R., Giannini, C., Non-causality in cointegrated systems: representation, estimation and testing. Oxford Bulletin of Economics and Statistics, Vol. 54, No. 3, pp.399-417, 1992.

12. Pesaran, M.H. and Shin, Y., cointegration and speed of convergence to equilibrium. Journal of econometrics, Vol.71, pp. 117-141, 1996.

13. Pesaran, M.H., Shin,Y. and smith, R.J., Structural analysis of vector error correction model with Exogenous I(1) variables. Journal of Econometrics, Vol. 97, pp. 293-343, 2000.

14. Sideris, D., Testing for long-run PPP in a system context: evidence for the U.S., Germany and Japan, Journal of International Financial Markets, Institutions and Money, Vol. 16, pp.143-154, 2006.

15. Taylor, A.M. and Taylor, M.P., The Purchasing Power Parity Debate, Journal of Economic Perspectives, Vol. 18, No.4, pp.135-58, 2004.

16. Taylor, M.P., Long-run purchasing power parity and real exchnage rates: introduction and overview, Applied Economics Letters, Vol. 16, No. 1, 2009.

17. Villavicencio, A.L., Nonlinearities or outliers in real exchange rates?, Economic Modelling, Vol. 25, pp.714-730, 2008. 


\section{APPENDIX 1}
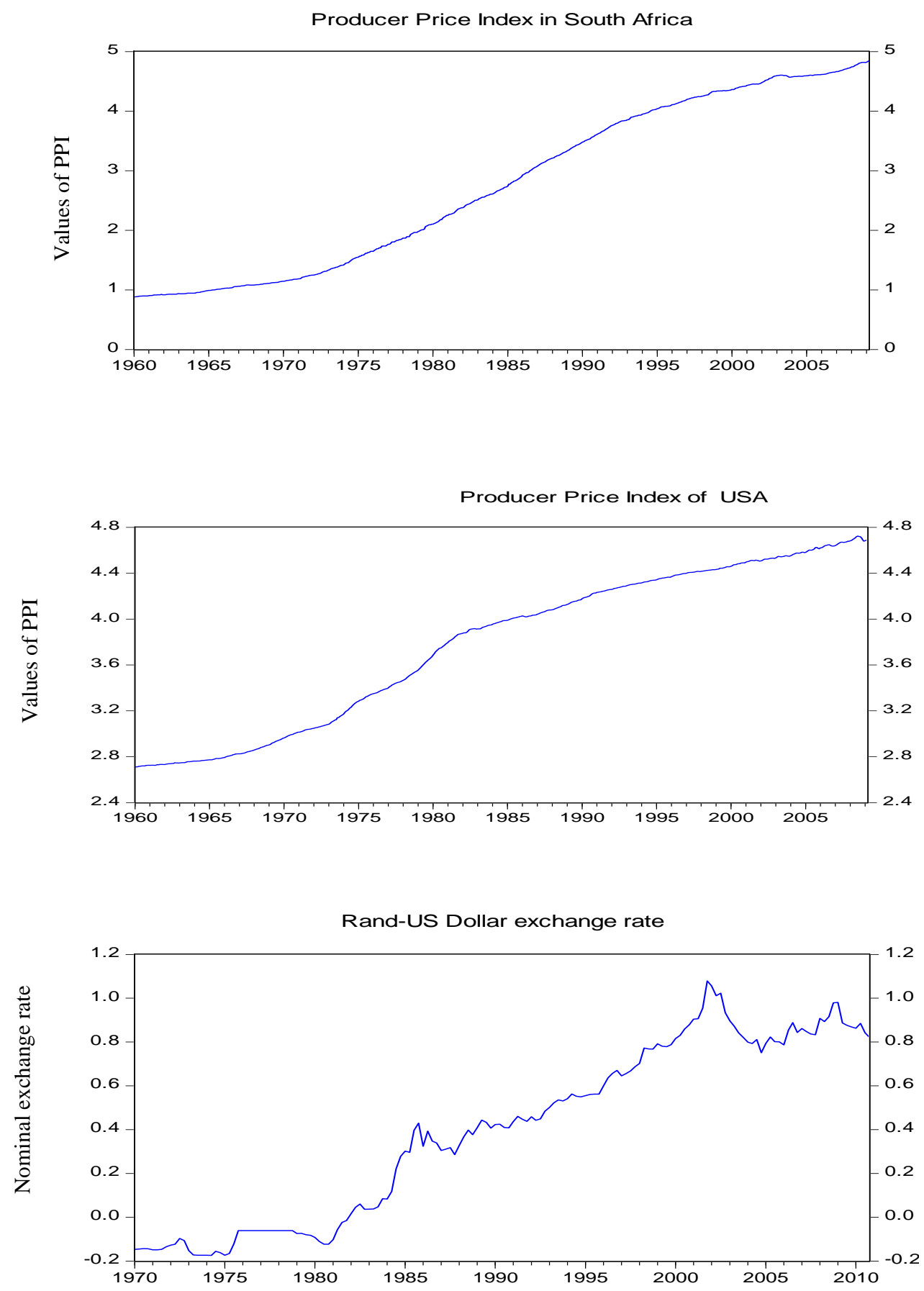

Figure 1: Natural logarithm of the Producer Price Index in South Africa and the US and the rand-dollar exchange rate 
NOTES 